\title{
Editorial
}

\section{Espírito, Igreja e missão}

Tratar da missão nos tempos atuais é uma tarefa instigante; e pontuar nesta a presença do Espírito Santo é outra tarefa particularmente exigente. Como a própria Palavra de Deus afirma, "o Espírito sopra onde quer" (Jo 3,8): Ele certamente marca Sua presença de formas variadas na Igreja e além da Igreja, solicitando sensibilidade para ver e discernir. Sob sua unção e inspiração, desenrola-se nos séculos a História da Salvação, sendo Ele mesmo "o guia” da missão na Igreja (Redemptoris missio n. 24). No interior desta compreensão encontra-se o movimento missionário da Igreja. Entende-se que a missão é sair de si para o outro, não por elã pessoal ou sentimento de autorrealização, mas como participação no plano de Deus em ato no mundo, nos eventos da Criação e Salvação. A missio Dei é a razão primeira da missio Ecclesiae participada por todos os batizados e batizadas, enviados como discípulos-missionários. Penetrar nesta razão e perceber como fez-se história em meio às luzes e sombras da história humana é tarefa da missiologia e áreas afins. Assim compreende-se o propósito deste dossiê: discernir e sinalizar a presença do Espírito Santo na atividade missionária da Igreja ao longo dos séculos.

No primeiro artigo, Valerian Fernandes (Índia) trata das "Biblical foundations for mission". Com sólida base bíblica, nota o quanto a Igreja tem sido missionária desde os tempos apostólicos até os dias atuais, motivada dinamicamente pelo Espírito Santo. O autor apresenta o perfil missionário de Jesus, que efetua verdadeiro salto na compreensão de sua religião ancestral, o Judaísmo. A Boa-Nova de Jesus assinala a novidade do Reino de Deus e sua realização messiânica, que iluminará toda a ação missionária da Igreja a partir dos apóstolos. Fernandes toma o quadro 
geral da missão apostólica no Novo Testamento e faz ali uma exploração honesta sobre o papel do Espírito Santo naquele período. O Espírito de Deus - manifesto em Pentecostes - se mostra, simultaneamente, fundamento e guia da missão na Igreja dos apóstolos.

A seguir, Joachim Andrade (Brasil) apresenta uma sinopse histórico-teológica da missão em seu artigo "Tradições, transições de transformações". Parte da missio Dei - a missão de Deus tradicionalmente entendida como saída divina para fora de Si mesmo, na direção da Criação - que constitui a origem ou arché da missão eclesial. Pois também os cristãos são chamados a sair na direção do outro, sair de uma cultura para outra e de um lugar para outro. O próprio Deus Trino inspira esta saída missionária, em sua decisão de vir ao encontro da Humanidade, desde a Criação até a Redenção, em seu Filho enviado na força do Espírito Santo. A Igreja preservou essa compreensão, dando origem à longa tradição missionária de início apostólico. Tradição dinâmica, vivida em aprendizado e discernimento nos diferentes períodos históricos. Andrade caracteriza este percurso como transição e transformação, expondo os modelos missionários sucessivos. Destaca o magistério do Concílio do Vaticano II e sua explicitação da natureza missionária da Igreja, radicada no ser e agir missionário de Deus Trino. A missão não é algo que a Igreja faz; mas algo que faz a Igreja, nascida da missio Dei. Esta explicitação favoreceu uma compreensão mais universal e inclusiva da missão, com novas transformações e conceitos: hoje o modelo conciliar ad gentes aponta para o modelo inter gentes, abrindo vias de encontro e diálogo em novos contextos missionários.

O terceiro artigo avança desde as perspectivas anteriores, com sua leitura pneumatológica da missão, especialmente no evangelista Lucas. Lina Boff (Brasil) apresenta "O Espírito na missão contemporânea" em três momentos: sinais de Sua presença nos cenários contemporâneos, dentro e fora da Igreja; fundamentação pneumatológica da missão no Novo Testamento, priorizando a teologia de Lucas; o chamado do Espírito para a missão em chave inclusiva. Nesta abordagem, Lina tem presente a multiplicidade de expressões pneumáticas de nossos dias, com um olhar na tradição bíblica e outro nos sinais recentes, especialmente a participação das mulheres no mandato missionário de Jesus. 
Em seguida, Joy Thomas (Índia) nos leva ao intrigante universo asiático com seu artigo "Mission in the Asia multi-religious context". Thomas observa que o momento atual é promissor para as sociedades, considerando os benefícios da globalização, o avanço tecnológico e os novos meios de comunicação e interação, como a Internet. Há uma efetiva aproximação entre as pessoas, com novas configurações de relação. Doutro lado, há também aumento da violência, crescente esquecimento de Deus e insegurança quanto ao futuro próximo, especificamente no contexto asiático. Além disso, fenômenos como o fanatismo religioso e o terrorismo abalam futuras esperanças. Nessa situação, a missão cristã redescobre seu sentido de Boa Nova. A Igreja acolhe os desafios e ensaia uma evangelização nova nos paradigmas e nas interlocuções, sobretudo no cenário multi-religioso. Com tal abordagem, o autor propõe-se rever nossas compreensões de evangelização no contexto da diversidade religiosa, questionando sobre novos recursos a serem usados, evidenciando a relevância do Evangelho nos dias de hoje.

O quinto artigo apresenta "A pneumatologia missionária de Papa Francisco em Evangelii gaudium”, pelas mãos de Marcial Maçaneiro e Diogo Marangon Pessotto (Brasil). Os autores partem de uma afirmação teológica na mencionada Exortação Apostólica, em que o Papa qualifica o Espírito Santo como "alma da Igreja evangelizadora" (Evangelii gaudium n. 261). Esta afirmação é central para a compreensão e a prática da missão evangelizadora, na esteira de documentos anteriores como Ad gentes (Concílio Vaticano II) e Redemptoris missio (João Paulo II). Há, porém, ênfases próprias do Papa Francisco, solicitando uma acurada leitura pneumatológica de toda a Evangelii gaudium. Maçaneiro e Pessotto traçam, assim, uma análise dos elementos pneumatológicos referidos à evangelização no documento, sejam suas ocorrências explícitas, sejam implícitas. Atenção especial mereceu o último capítulo de Evangelii gaudium - eminentemente pneumatológico - que reenvia aos inícios da Exortação a partir de uma consideração pneumatológico-trinitária aplicada à missão. Dos elementos pneumatológicos analisados destacam-se: a primazia do Espírito na evangelização, a começar da Unção messiânica de Jesus; o evento de Pentecostes e sua força paradigmática para a missão; a dinamicidade do Espírito Santo como espírito da evangelização; a necessidade de uma dócil abertura dos evangelizadores à 
ação do mesmo Espírito. Por fim, a análise revela os vínculos estreitos entre Pneumatologia, Eclesiologia e Evangelização.

O dossiê dedica, ainda, uma atenção particular à teologia pentecostal sobre o diálogo inter-religioso, ainda em elaboração, especialmente no Brasil. Adriano Lima (Brasil) aborda o tema em chave pneumatológica em seu artigo "A presença universal do Espírito de Deus e a criação: elementos para o diálogo inter-religioso na teologia pentecostal". Ciente do quanto esta reflexão faz-se necessária em contextos de sectarismo e proselitismo, Lima entende que a presença universal do Espírito de Deus, manifesta inclusive nas línguas de Pentecostes, constitui um convite ao Pentecostalismo na sua compreensão da diversidade religiosa. Pois a ação universal do Pneuma e o cuidado da Criação se articulam intimamente, possibilitando a ponte entre Criação e Salvação numa perspectiva pentecostal mais aberta e inclusiva. Assim, a reflexão prospecta uma teologia pentecostal em vista do diálogo inter-religioso, de fonte bíblica e de suporte ensaístico, aproximando teólogos pentecostais e católicos à base dos argumentos. Lima conclui que o Espírito está em todo ser que vive, comunicando o propósito de Deus para a Criação e enredando todas as coisas na Redenção universal: eis aqui uma razão interna da fé pentecostal para comprometer-se com o diálogo inter-religioso.

Luiz Balsan (Brasil) assina o sétimo artigo sobre "Espiritualidade missionária". Atento às eventuais compreensões redutivas de espiritualidade, compreendida apenas como "vida interior", Balsan discorre sobre os elementos fundamentais de uma espiritualidade cristã missionária no sentido pleno de Vida no Espírito. A oração entra na vida e a vida entra na oração, no compasso dos sinais dos tempos, do serviço fraterno das obras de misericórdia. Passando por Teilhard de Chardin, Paulo VI, Ellacuría, Codina e Casaldáliga, o autor valoriza os espaços da vida e das relações como lugar do Espírito, sob o signo da Encarnação do Verbo. Amar o mundo e servir à humanidade pela causa do Evangelho perfilam o missionário como "sal e luz" (Mt 6,14-15).

Concluindo o dossiê, Claudete Beise Ulrich, Valéria Cristina Vilhena e Leicyelem von Rondow da Silva (Brasil) recuperam a memória da missionária ordenada Frida M. Strandberg, enviada pela Igreja Filadélfia de Estocolmo (Suécia) em 1917, para atuar na missão brasileira 
das Assembleias de Deus. As autoras partem de pesquisa histórica, biográfica e documental, para nos apresentar "Frida Maria Strandberg, uma missionária esquecida: movida pela Ruah e impedida pelos homens de Deus". Apesar de perseguida, depois invisibilizada pela narrativa oficial, sua memória vem sendo recuperada desde 2009 como força mobilizadora das mulheres na Igreja Assembleia de Deus. Com este estudo, as autoras trazem um caso biográfico à reflexão sobre o Espírito e a Missão neste dossiê, aproximando ainda mais o cotidiano missionário e a reflexão teológica, em ótica feminina.

Este número de Pistis \& Praxis prossegue com mais cinco contribuições:

Ronaldo de Paula Cavalcante trata das "Espiritualidades protestantes" com um enfoque preciso: "A piedade na tradição luterana em torno à justificação pela fé”. O autor considera elementos históricos e teológicos em sua abordagem da pietas luterana, edificada sobre as Escrituras na tensão entre o enrijecimento dogmático católico e o radicalismo protestante. A piedade luterana busca equilíbrio entre posturas extremas, combinando doutrina e espiritualidade. Por um lado, contribuiu para a Modernidade pós-reforma; por outro, revisitou posições teológicas e espirituais dos antigos e medievais, valorizados como exemplo de devoção.

Seguindo a temática do Protestantismo, temos Claudio de Oliveira Ribeiro com sua pesquisa sobre as "Raízes protestantes da teologia latino-americana da libertação". O autor examina as vertentes teológicas protestantes que marcaram a gênese da Teologia da Libertação, com análise em dois tempos: retoma a primeira geração de teólogos da libertação, com suas correspondentes práticas sociais e ecumênicas (José Míguez-Bonino, Júlio de Santa Ana, Rubem Alves); depois volta-se à teologia feminista (Elza Támez, Marcella Althaus-Reid) desenvolvida nas décadas seguintes. Desta produção, destacam-se a crítica bíblica à economia política e o tema da justificação pela fé, ambos preciosos para a tradição teológica protestante, sem esquecer os temas de sexualidade humana geralmente latentes às discussões.

Adilson Cristiano Habowski e Elaine Conte analisam a possível relação entre a evangelização cristã e as tecnologias digitais, no recente contexto de midiatização da cultura. No sugestivo artigo "Os desafios da 
evangelização com as novas tecnologias digitais" os autores buscam identificar as (in)viabilidades de propagação e vivência da fé por meio das tecnologias no cenário social, político e religioso que se descortina no século XXI. Tema tão desafiante quanto promissor, além de ser cada vez mais necessário para a nova evangelização nas sociedades atuais. Habowski e Conte detectam certa banalização das coisas sagradas e das mensagens religiosas no ciberespaço, sugerindo um cuidado particular: que a evangelização mediante tecnologias digitais cultive a postura reflexiva quanto à vida e à construção da identidade, com atenção aos valores e ao sentido que o Evangelho comunica.

David Mesquiati de Oliveira e Alessandro Rocha aproximam teologia e sociologia, com seu estudo sobre "Pentecostalismo e empoderamento de identidades marginalizadas". Partindo do pensamento de Gilbert Durand, os autores privilegiam a margem social e eclesial como lugar de tomada de consciência, no âmbito pentecostal. O olhar sociológico busca mapear os movimentos entre margem e centro, com seus encontros e acessos que interferem na identidade dos sujeitos. O olhar teológico examina as potencialidades do sacerdócio de todos os cristãos como elemento de pro-vocação desde as margens. O estudo não se detém em categorias hipotéticas, mas acompanha a história de vida de dois personagens do meio pentecostal: um homem negro e pobre; e uma mulher migrante.

Afonso Murad encerra esta edição, indagando sobre a passagem "Do mundo vulnerável a outro mundo possível: Contribuição de Riechmann e da Laudato Si para tecnociência e sustentabilidade”. Como se nota, Murad aproxima Jorge Riechmann (ambientalista) e Jorge M. Bergoglio (Papa Francisco) pelo viés do pensamento ecológico. Segundo Riechmann, a tecnociência modifica de tal maneira a natureza e a sociedade, que torna o mundo mais vulnerável. Donde a necessidade de mudanças estruturais, para redimensionar a tecnociência em prol de uma sociedade sustentável. As sugestões vão da gestão criativa a um novo contrato social com a Ciência e a Tecnologia. Já o Papa Francisco, no Capítulo III da encíclica Laudato si, avalia o paradigma tecnocrático como unidimensional e, portanto, limitado para uma abordagem integral das questões socioambientais. Similar ao posicionamento de Riechmann, também o Papa propõe uma série de iniciativas em vista da sustentabilidade da vida humana e 
planetária. Murad pontua essas duas contribuições, inserindo-as no quadro mais amplo da ecoteologia.

A todos e todas, boa leitura. Aos autores, avaliadores e assistentes que colaboraram com esta Revista em 2018, a nossa gratidão, certos de seguir juntos na pesquisa, intercâmbio e publicação.

Deo gratias!

Prof. Dr. Joachim Andrade

Prof. Dr. Marcial Maçaneiro 